\title{
SENAM JANTUNG SEHAT BERPENGARUH TERHADAP PERUBAHAN HEMODINAMIK PADA PASIEN HIPERTENSI
}

\author{
Agung Setiawan Rahmattilan, Muhammad Rizky Wardhana*, Magdalena Nazara \\ Program Studi S1 Keperawatan, Fakultas Keperawatan dan Kebidanan, Universitas Prima Indonesia, Jl. \\ Danau Singkarak, Gg. Madrasah, Kel. Sei Agul, Kec. Medan Barat, Medan, Sumatera Utara 20117 \\ *rizkywardana929@gmail.com
}

\begin{abstract}
ABSTRAK
Hipertensi merupakan sebuah masalah bagi kesehatan tubuh pada sistem kardiovaskular yang sudah biasa terjadi pada orang - orang lanjut usia. Olahraga senam jantung sehat seri pertama adalah salah satu cara pengendalian hipertensi pada lanjut usia. Tujuan dilakukannya penelitian yang dilakukan ini untuk membuktikan adanya pengaruh dari gerakan senan jantung sehat terhadap hemodinamik pada pasien hipertensi di Panti Jompo Yayasan Guna Budi Bakti Medan. Desain yang dipakai untuk penelitian ini disebut Quasi Experiment dengan Control Group. Menggunakan teknik Purposive Sampling yang berisi 30 orang dan dibagi menjadi 15 orang grup kontrol dan 15 oranggrup intervensi. Intervensi diberikan selama tujuh hari. Tekanan darah yang berbeda pada setiap grup diuji menggunakan uji-t berpasangan serta selisih tekanan darah diantara grup kontrol dan juda grup intervensi diuji menggunakan uji t-Independent. Dari hasil penelitian ini membuktikan adanya dampat dari senam jantung sehat terhadap hemodinamik dalam grup intervensi saat sesudah dan sebelum senam jantung sehat dengan nilai sig. (2-tailed) untuk tekanan sistol adalah $(0,000)$, nilai sig. (2-tailed) untuk tekanan diastol adalah $(0,003)$, tekanan sistol turun dalam tujuh hari sebesar $19,33 \mathrm{mmHg}$ dan11,33 $\mathrm{mmHg}$ untuk tekanan diastol. Dalam grup kontrol tidak ada pengaruh terhadap tekanan darah dengan hasil sig. (2tailed) pada tekanan sistol sebesar $(0,582)$ dan hasil nilai sig. (2-tailed) untuk tekanan diastol sebesar $(0,849)$.
\end{abstract}

Kata kunci: hipertensi; lanjut usia; senam jantung sehat

\section{HEALTHY HEART EXERCISE EFFECTS ON HEMODYNAMIC CHANGES IN HYPERTENSION PATIENTS}

\begin{abstract}
Hypertension is a health problem in the cardiovascular system that often occurs in the elderly. Type 1 cardio gymnastics is one way to control hypertension in the elderly. The purpose of this research was to prove the effect of cardio gymnastics on hemodynamics in the elderly at Panti Jompo Guna Budi Bakti Medan. The design used in this research is a Quasi Experiment with a Control Group.Using purposive sampling technique consisting of 30 respondents and divided into 15 respondents in the control group and 15 respondents in the intervention group. The intervention was given for seven days. Different blood pressures in each group is tested using paired t test and differences in blood pressure between the control group and the intervention group tested using the Independent t test. The results of this research prove that there is an effect between cardio gymnastics on hemodynamics in the intervention group before and after healthy heart gymnastics with a sig. (2-tailed) for systolic blood pressure (0.000), sig. (2-tailed) for diastolic blood pressure (0.003) and a decrease in blood pressure for seven days for systolic blood pressure of $19.33 \mathrm{mmHg}$ and for diastolic blood pressure of $11.33 \mathrm{mmHg}$. Whereas in the control group there was no effect on blood pressure with $p$ value for systolic blood pressure (0.582) and sig. (2-tailed) for diastolic blood pressure (0.849).
\end{abstract}


Keywords: cardio gymnastics; elderly; hypertension

\section{PENDAHULUAN}

Pada jaman modern saat ini dimana peningkatan pengetahuan serta peralatan disegi kesehatan, telah berhasil meningkatkan Angka Harapan Hidup sedikit demi sedikit setiap tahunnya. Saat ini Usia Harapan Hidup (UHH) dengan rata-rata dunia pada tahun 2010-2015 sekitar 70\%, dan pada tahun 2015-2020 angka tersebut mencapai $71 \%$. Angka ini terus meningkat dan diperkirakan pada tahun 2100 angka UHH menjadi 81,8\% (Kemenkes RI 2014).

Sistem kardiovaskuler adalah sistem organ yang terkait dengan pembuluh darah dan jantung (Fadli, 2018). Seiring naiknya angka usia harapan hidup, pasien hipertensi tidakhanya jadi beresiko juga menderita masalah penyakit jantung, tapi juga beragam penyakit lain seperti penyakit yang menyerang ginjal, pembuluh darah, dan saraf.

\section{World Health Organization (WHO)} juga memperkirakan di tahun 2020 penyakit yang berkaitan dengan sistem organ kardiovaskular akan menyebabkan kematian hingga sekitar $73 \%$ dan angka kesakitan di seluruh dunia mencapai $60 \%$. Negara yang merasakan dampaknya adalah negara berkembang termasuk negara Indonesia (Rahajeng \& Tuminah, 2009). Dapat di lihat pada tahun 2020, tercatat rerata angka harapan hidup untuk laki-laki adalah 73,46 tahun. sedangkan rerata angka harapan hidup untuk perempuan adalah 69,59 tahun. Telah naik dibandingkan di tahun 2015 dimana rerata angka harapan hidup untuk lakilaki adalah 72,78 tahun dan rerata angka harapan hidup untuk perempuan adalah 68,93 tahun (BPS, 2020).
Semakin besar risiko jika semakin tinggi tekanan darahnya. (Price \& Wilson, 2016). Tujuan dari penelitian ini secara umum ialah mengetahui adanya dampak gerakan senam jantung sehat terhadap perubahan hemodinamik pada pasien hipertensi yang ada di Panti Jompo Yayasan Guna Budi Bakti Medan tahun 2021. Dengan demikian para lansia akan mampu memperlambat proses penuaan dini, tetap sehat dan mandiri selama mungkin. (Lalarni, 2015).

Hemodinamik dikatakan baik bila volume / komponen darah cukup, kontraktilitas jantung baik, dan tahanan pembuluh darah sistemik (systemic vascular resistancy) baik sehingga semua organ-organ tubuh dapat berfungsi dengan baik. (Robert, 2020). Perlu adanya kontrol terhadap kenaikan tekanan darah karena peningkatan tekanan darah yang berkepanjangan merusak pembuluh darah di organ target (jantung, ginjal, otak dan mata) (Brunner \& Suddarth, 2013).

Tujuan penelitian ini secara khusus ialah untuk mencari gambaran karaktersistik hipertensi pada lanjut usia yang ada di Panti Jompo Yayasan Guna Budi Bakti Medan tahun 2021, untuk mencari gambaran tekanan darah saat pretes dan juga posttest dalam grup intervensi di Panti Jompo Yayasan Guna Budi Bakti Medan tahun 2021. Untuk mencari gambaran tekanan darah saat pretes dan posttes dalam grup kontrol di Panti Jompo Yayasan Guna Budi Bakti Medan tahun 2021.

\section{METODE}

Penelitian ini lolos etik dengan nomor 015/KEPK/UNPRI/IV/2021. Jenis penelitian ini merupakan analitik 
kuantitatif dan desain penelitian ini menggunakan Quasi Eksperimental. Penelitian Quasi Eksperimental merupakan suatu rancangan penelitian yang bertujuan mengungkap adanya hubungan sebab dan akibat dengan melihat perbandingan antar grup kontrol di samping grup intervensi. Rancangan penelitian yang dipakai di penelitian ini merupakan non-equivalent control group dengan pretes-posttes design. Penelitian ini memakai control-group tanpa randomiasi. Tempat penelitian ada di Panti Jompo Yayasan Guna Budi Bakti Medan. Waktu dilaksanakannya penelitian ini dirancang pada bulan April 2021.

Populasi dalam penelitian ini merupakan pasien dengan masalah hipertensi yang ada di Panti Jompo Yayasan Guna Budi Bakti Medan. Jumlah populasi pasien dengan masalah hipertensi sebanyak 40 orang yang ada di panti jompo Yayasan Guna Budi Bakti Medan. Sampel dalam penelitian ini adalah pasien dengan masalah hipertensi yang ada di Panti Jompo YayasanGuna Budi Bakti Medan. Penelitian ini menggunakan quasi eksperimental dengan mengambil sampel sebanyak 30 orang dan terbagi menjadi grup intervensi 15 orang dan grup kontrol 15 orang.
Aspek utama dalam pengukuran pengaruh senam jantung sehat terhadap perubahan hemodinamik pada pasien hipertensi di Panti Jompo Yayasan Guna Budi Bakti Medan tahun 2021 yaitu Pelaksanaan senam jantung sehat dengan durasi 30-40 menit dipagi hari sesuai dengan instruksi yang dianjurkan oleh peneliti yaitu satu kali sehari dan dilakukan pengumpulan data dengan menggunakan teknik sampling yang dilakukan setelah bangun pagi (Posttest) dan dilakukan setiap hari dalam rentan waktu selama tujuh hari. Persiapaan alat-alat dan bahan-bahan yang dibutuhkan dalam penelitian ini yaitu: sphygmomanometer dan stetoskop.

Pengaturan dilakukan pada sphygmomanometer terlebih dahulu. Sphgymomanometer aneroid harus membaca di nol bila tidak terdapat tekanan udara didalam manset (Wiillianms, 2014). Penting untuk meminta lansia untuk duduk tenang selama 3-5 menit sebelum mulai dilakukan pengukuran tekanan darah. Lansia yang mengalami deconditioning membutuhkan waktu rehat agar kondisi tubuh kembali ke kondisi normalnya meskipun setelah mengalami stres minor (Dewi, 2014).

\section{HASIL}

Tabel 1.

Usia Responden $(\mathrm{n}=30)$

\begin{tabular}{cccc}
\hline \multicolumn{3}{c}{ Usia } \\
\hline Kelompok & Mean & SD & Min - Max \\
\hline Intervensi & 66,4 & 8,304 & $53-81$ \\
\hline Kontrol & 72,86 & 7,631 & $61-88$ \\
\hline
\end{tabular}


Tabel 2.

Jenis Kelamin Responden ( $\mathrm{n}=30)$

\begin{tabular}{lcccccc}
\hline \multicolumn{1}{c}{ Jenis Kelamin } \\
\hline \multicolumn{1}{c}{ Grup } & \multicolumn{2}{c}{ Perempuan } & \multicolumn{2}{c}{ Laki - Laki } & \multicolumn{2}{c}{ Total } \\
\hline Intervensi & $\mathrm{f}$ & $\%$ & $\mathrm{f}$ & $\%$ & $\mathrm{f}$ & $\%$ \\
\hline Kontrol & 12 & 80 & 3 & 20 & 15 & 100,0 \\
\hline
\end{tabular}

Tabel 3.

Gambaran Besaran Perbedaan-Rerata Tekanan Darah pada Pasien Penderita Hipertensi Dilihat dari Segi Pengukuran Hari Ketujuh dalam Grup Intervensi $(n=15)$ Grup Intervensi

\begin{tabular}{lllll}
\hline & & \multicolumn{1}{c}{ Mean } & \multicolumn{1}{c}{ SD } & \multicolumn{1}{c}{ Min - Max } \\
\hline \multirow{2}{*}{ TDS } & Pretest & 134 & 5,071 & $130-140$ \\
\cline { 2 - 5 } & Posttest & 120,67 & 7.037 & $110-130$ \\
\hline \multirow{2}{*}{ TDD } & Pretest & 91,33 & 7,432 & $80-100$ \\
\cline { 2 - 5 } & Posttest & 82,67 & 4,577 & $80-90$ \\
\hline
\end{tabular}

Tabel 4.

Gambaran dari Perbedaan RerataTekanan Darah pada-Pasien Penderita Hipertensi Dilihat dari Segi Pengukuran Hari Ke Tujuh dalam Grup Kontrol ( $\mathrm{n}=15)$

\begin{tabular}{|c|c|c|c|c|}
\hline \multicolumn{5}{|c|}{ Grup Kontrol } \\
\hline & & Mean & SD & $\operatorname{Min}-\operatorname{Max}$ \\
\hline \multirow[t]{2}{*}{ TDS } & Pretest & 133,33 & 7,237 & $120-140$ \\
\hline & Posttest & 16,66 & 8,997 & $120-150$ \\
\hline \multirow[t]{2}{*}{ TDD } & Pretest & 93,33 & 6,172 & $80-100$ \\
\hline & Posttest & 92 & 10,823 & $80-120$ \\
\hline
\end{tabular}

Tabel 5.

Perbedaan dari BesaranRerata Tekanan Darah pada Pasien Penderita Hipertensi Sesudah dan Sebelum Tindakan dalamGrup Intervensi $(n=15)$

\begin{tabular}{|c|c|c|c|c|c|c|c|c|c|}
\hline \multirow{2}{*}{$\begin{array}{l}\text { Vari } \\
\text { abel }\end{array}$} & & \multicolumn{5}{|c|}{ Paired Difference } & \multirow{2}{*}{$\begin{array}{c}\mathrm{P} \\
\text { Value }\end{array}$} & \multirow[b]{2}{*}{$t$} & \multirow{2}{*}{ Eta } \\
\hline & & Mean & SD & Mean & SD & $95 \mathrm{CI}$ & & & \\
\hline \multirow{2}{*}{ TDS } & Pretest & 134 & 5,071 & \multirow{2}{*}{13,33} & \multirow{2}{*}{7,237} & $9,325-$ & \multirow{2}{*}{$<0,001$} & \multirow{2}{*}{7,135} & \multirow{2}{*}{0.320} \\
\hline & Posttest & 120,67 & 7,037 & & & 17,341 & & & \\
\hline \multirow{2}{*}{ TDD } & Pretest & 91,33 & 7,432 & \multirow{2}{*}{8,66} & \multirow{2}{*}{6,399} & $5,123-$ & \multirow{2}{*}{$<0,001$} & \multirow{2}{*}{5,245} & \multirow{2}{*}{0.518} \\
\hline & Posttest & 82,67 & 4,577 & & & 12,211 & & & \\
\hline
\end{tabular}


Tabel 6.

Perbedaan dari Besaran Rerata Tekanan Darah pada Pasien Penderita Hipertensi

Sebelum serta Sesudah Tindakan pada Grup Kontrol $(n=15)$

\begin{tabular}{|c|c|c|c|c|c|c|c|c|c|}
\hline \multirow{2}{*}{ Variabel } & & \multicolumn{5}{|c|}{ Paired Difference } & \multirow{2}{*}{$\begin{array}{c}\mathrm{P} \\
\text { Value }\end{array}$} & \multirow{2}{*}{$\mathrm{t}$} & \multirow{2}{*}{ Eta } \\
\hline & & Mean & SD & Mean & SD & $95 \mathrm{CI}$ & & & \\
\hline \multirow[b]{2}{*}{ TDS } & Pretest & 133,33 & 7,237 & & & $-8,316$ & & & \\
\hline & Posttest & 136,66 & 8,997 & $-3,333$ & 8,997 & $\begin{array}{c}- \\
1,649\end{array}$ & 0,137 & $-1,435$ & 0.402 \\
\hline \multirow[b]{2}{*}{ TDD } & Pretest & 93,33 & 6,172 & \multirow[b]{2}{*}{1,333} & \multirow[b]{2}{*}{11,255} & $-4,899$ & \multirow[b]{2}{*}{0,444} & \multirow[b]{2}{*}{0,459} & \multirow[b]{2}{*}{0,214} \\
\hline & Posttest & 92 & 10,823 & & & $\begin{array}{c}- \\
7,566\end{array}$ & & & \\
\hline
\end{tabular}

Tabel 7.

Gambaran Besaran Perbedaan Jarak Rerata Tekanan Darah untuk Pasien Penderita Hipertensi Dalam Grup Intervensi dan Grup Kontrol $(\mathrm{n}=30)$

\begin{tabular}{|c|c|c|c|c|c|c|c|c|}
\hline \multirow{2}{*}{ Variabel } & \multicolumn{2}{|c|}{ Intervensi } & \multicolumn{2}{|c|}{ Kontrol } & \multirow{2}{*}{$95 \mathrm{CI}$} & \multirow{2}{*}{$\begin{array}{c}\mathrm{P} \\
\text { Value }\end{array}$} & \multirow{2}{*}{$\mathrm{t}$} & \multirow{2}{*}{ Eta } \\
\hline & Mean & $\mathrm{SD}$ & Mean & SD & & & & \\
\hline TDS & 13,33 & 7,237 & $-3,33$ & 8,997 & $\begin{array}{c}-23,174- \\
-10,158\end{array}$ & $<0.001$ & $-5,493$ & 0,370 \\
\hline TDD & 8,66 & 6,399 & 1,33 & 11,255 & $\begin{array}{c}-15,014- \\
0,347\end{array}$ & 0,060 & $-2,048$ & 0,175 \\
\hline
\end{tabular}

\section{PEMBAHASAN}

Tabel 1. didapati dalam grup intervensi rerata umur subjek penelitian adalah 66,4 tahun (SD 8,3 tahun). Subjek penelitian yang termuda berumur 53 tahun dan yang tertua berumur 81 tahun. Sedangkan dalam grup kontrol, umur rerata adalah 72,84 tahun (SD 7,6 tahun). Dimana subjek penelitian yang termuda berumur 61 tahun dan yang tertua berumur 88 tahun. Menurut peneliti ini menunjukan bahwa umur adalah salah satu faktor terjadinya hipertensi karena terjadinya penurunan fungsi organ di masa lanjut usia.

Hasil ini sesuai dengan penelitian yang dilaksanakan Puspa (2016) dimana orang berusia lebih dari 60 tahun akan lebih beresiko mengalami masalah kardiovaskular dan mengalami hipertensi dikarenakan dampak dari terjadi perubahan struktural dan fungsional pada lanjut usia. Didukung juga dari hasil penelitian yang dilaksanakan Neni (2018) di desa patemon, kec. Bojongsari yang menunjukkan bahwa lanjut usia mengalami penurunan tekanan darah sistol maupun diastol dan terjadi perubahan kondisi fisik yang lain.

Tabel 2. didapati bahwa $80 \%$ subjek penelitian digrup intervensi merupakan perempuan dan dalam grup kontrol didapati $33,3 \%$ subjek penelitian merupakan perempuan. Menurut peneliti ini menunjukan bahwa jenis kelamin adalah salah satu faktor terjadinya hipertensi. Hasil ini sesuai dengan penelitian yang dilaksanakan Puspa (2016) yang berpendapat bahwa ada perbedaan dari jenis kelamin dalam kaitannya antara usia dengan tekanan darah sistolik dimana laki-laki memiliki tekanan darah sistolik yang lebih tinggi daripada wanita selama masa dewasa awal dan dewasa menengah, sedangkan pada wanita cenderung memiliki tingkat 
tekanan darah sistolik yang lebih tinggi setelah masa dekade keenam.

Tabel 7. rerata perbedaan angka tekanan sistol dihari ketujuh dalam grup kontrol adalah $-3,33$, sedangkan pada grup intervensi perbedaaan angka tekanan darah di hari ketujuh pada grup kontrol adalah 13,33. Nilai uji statistik didapati nilai sig. $(2$-tailed $)=(0,000)$, dimana pada alpa $5 \%$ terdapat perbedaan yang jelas diantara tekanan sistol yang adaantaragrup intervensi dan juga grup kontrol. Dilihat dari besar pengaruhnya, didapati nilai Eta 0,370. Menurut Woodrow (2014) Eta lebih dari 0,37 menunjukan besarnya pengaruh tekanan sistol pada grup kontrol dan grup intervensi.

Rerata perbedaaan angka tekanan diastol dihari ketujuh ketika pretes dan posttesdalamgrup kontrol adalah 1,33, sedangkan rerata perbedaaan tekanan darah diastol dihari ketujuh pada pretes dan posttes dalam grup intervensi adalah 8,66 dari uji statistik didapati nilai sig. (2-tailed) $=(0,060)$, yang diartikan sebagai nilai alpa $5 \%$ dimana terdapat perbedaan besar antara tekanan darah diastol dalam grup kontrol dan juga grup intervensi. Dari besaranya pengaruh, terdapat nilai Eta 0,175 . Menurut Woodrow (2014) Eta lebih dari 0,37 yang berarti ada pengaruh besar antar tekanan diastol dalam grup intervensi dan juga grup kontrol.

Hasil tersebut peneliti berpendapat bahwa gerakan senam jantung sehat dapat mempengaruhi perubahan hemodinamik pada pasien hipertensi. Pendapat tersebut sesuai dengan penelitian yang dilaksanakan Puspa (2016) yang menyatakan bahwa kegiatan fisik atau berolahraga dengan teratur bisa menurunkan tekanan darah sistol dan diastol berkaitan dengan penurunan tahanan perifer yang dijelaskan melalui beberapa mekanisme yaitu aktivitas system jaringan saraf simpatik, respon organ vascular, hiperinsulinemia dan resistensi insulin, serta system rennin-angiotensin yang pada akhirnya akan menurunkan tekanan darah.

Latihan fisik mampu menurunkan tekanan darah pada lanjut usia dengan penderita hipertensi dan dengan demikian terdapat nilai yang akan berbanding lurus dengan penurunan tekanan arteri rata rata dengan melihat nilai perubahan tekanan darah sistol dan diastol sebelum dan setelah diberikan latihan (Mugianti, 2018). Selain itu, dalam penelitian yang dilaksanakan Widianti (2016) dikatakan bahwa senam bisa meningkatkan daya tahan tubuh setelah latihan dengan teratur dan penelitian menyebutkan adanya efek minimal yang didapatkan dengan mengikuti senam yaitu selalu merasa bahagia dan bergembira, tidur yang lebih nyenyak, dan pikiran yang tetap segar. Juga sejalan dengan penelitian yang dilaksanakan Afani (2019) di wilayah kerja puskesmas Dau, Kabupaten Malang yang menunjukan hasil bahwa ada 29 subjek penelitian dalam kategori sangat baik ketika melakukan gerakan senam jantung sehat dengan hemodinamik terutama tekanan darah yang berefek pada perubahan tekanan arteri rata-rata yang mengalami penurunan (batas normal) setelah melakukan senam .

\section{SIMPULAN}

Tekanan darah dalam grup intervensi didapatkan nilai dari sig. (2-tailed) dari TDS adalah $(0,000)$. Serta nilai sig. (2tailed) pada TDD sebesar $(0,000)$ maka didapatkan nilai sig. (2-tailed) adalah $(<0,05)$ dimana artinya ada dampak gerakan senam jantung sehat pada tekanan darah dalam grup intervensi. 
Sementara, dalam grup kontrol didapatkan sig. (2-tailed) pada TDS sebesar $(0,137)$ dan nilai dari sig. (2tailed) pada TDD adalah $(0,444)$ maka didapat nilai dari sig. (2-tailed) adalah $(>0,05)$ dimana artinya tidak terdapat dampak apapun dalam grup kontrol.

Hasil dari uji statistic dalam grup intervensi didapatkan selisih pada TDS sebesar -13,33 dan dalam grup kontrol selisih pada TDS sebesar -3,33 dengan nilai sig. (2-tailed) sebesar $(0,000)$. Dalam grup intervensi didapatkan TDD sebesar 8,66 dan dalam grup kontrol perbedaan TDD adalah sebesar 1,33 dengan nilai sig. (2-tailed) adalah sebesar 0,060. Oleh karena itu, berdasarkan data ini ditemui adanya perbedaan yang jelas antar tekanan sistol dan tekanan diastol dalam grup kontrol dan grup intervensi.

\section{DAFTAR PUSTAKA}

BPS. (2020). Indonesia Dalam Angka 2020. Badan Pusat Statistik. http://www.bps.go.id [25 Mei 2021]

Brunner, Suddarth, (2013). Buku Ajar Keperawatan Medikal Bedah. Edisi 8 Vol. 2. Jakarta : EGC.

Depkes RI (2014). Hipertensi. Jakarta : Pusat Data dan Informasi Kementrian Kesehatan RI.

Dewi, Sofia Rhosma (2014). Buku Ajar Keperawatan Gerontik. Yogyakarta : Deepublish.

Fadli, F. (2018). Pengaruh Relaksasi Otot .......Progresif Terhadap Perubahan .......Tekanan Darah Pada. Pasien .......Hipertensi. Jurnal Ilmiah Kesehatan .......Diagnosis, 12(3), 249-253.
Lalarni, Husnu Khatimah (2015). Pengaruh Senam Jantung Sehat Seri $V$ terhadap Kebugaran dan Lemak Tubuh pada Anggota Posyandu Lansia Amrih Sehat Kec. Bergas Semaran. SKRIPSI S1 Fakultas Ilmu Keolahragaan, Universitas Semarang

Mugiarti, Neni (2018). Penerapan Senam Lansia Untuk Penuruna Tekanan Darah Pada Kelompok Lansia Dengan Hipertensi Di Desa Patemon Kecamatan Bojongsari.

http://repository.ump.ac.id/8286/9 .pdf [25 Mei 2021]

Nabila, Afani (2019). Gambaran Senam Jantung Sehat Dan Kualitas Hidup Pasien Hipertensi Yang Mengikuti Program Pengelolaan Penyakit (Prolanis) Di Wilayah Kerja Puskesmas Dau Kabupaten.

Priadi, P. A. (2016). Pengaruh Senam Jantung Sehat Terhadap Tekanan Darah Pada Lansia Hipertensi Di PSTW Budi Mulia 03 Margaguna Jakarta Selatan (Bachelor's Thesis, FKIK UIN Jakarta).

Price A. Sylvia, Wilson M. Lorraine (2016). Patofisiologi Konsep Klinis Proses Proses Penyakit. Jakarta : Buku Kedokteran EGC.

Rahajeng, E., \& Tuminah, S. (2009). Prevalensi hipertensi dan determinan nya di Indonesia. Majalah

Kedokteran Indonesia, 59 (12), 580-587.

Robert, (2020). Buku Ajar Pemantauan Hemodinamik Pasien. Jakarta : UKI Press

Swarjana, I.K., \& SKM, M. (2012). Metodologi penelitian 
kesehatan. Penerbit Andi.

Widianti, A. T. \& Proverawati, A. (2016). Senam Kesehatan. Yogyakarta: Nuha Medika.

Williams, Wilkins (2014). ACSM's Resource Manual for Guidelines for .........Exercise Testing and Prescription. American College of Sports Medicine.

Woodrow, Lindy (2014). Writing about Quantitaif Research in Applied Linguistic. USA : Palgrave McMillan.

World Health Organization.(2016).

Ageing and Life Course.

World Health Organization.(2016) Data Penyakit Terbanyak di Dunia.

Wardian, J., \& Sun, F. (2016). Social Work in Health Care Factors Associated With DiabetesRelated Distress : Implications for Diabetes Self Management.

Wratsongko, M .(2018). Senam Ergonomik dan Pijat Getar Saraf. Jakarta:P Kawan Pustaka

Zainudin, M., Utomo, W. Dan Herlina. (2016). Hubungan Stres Dengan Kualitas Hidup Penderita Diabetes Mellitus Tipe 2. JOM. 